\title{
Insulin lispro low mixture twice daily vs basal insulin glargine once daily and prandial insulin lispro once daily as insulin intensification strategies in patients with type 2 diabetes: A Latin American subpopulation analysis of a randomized trial
}

\begin{abstract}
Douglas Eugenio Barbieri", Ran Duan, Jorge Gross, Bruno Linetzky, Janaina Martins De Lana, Arturo Rojas, Georgina Sposetti, Oded Stempa, Angel Rodriguez
\end{abstract}

From 20th Brazilian Diabetes Society Congress

Porto Alegre, Brazil. 11-18 November 2015

\section{Background/aim}

This post-hoc analysis examined the efficacy and safety of twice-daily insulin lispro low mixture (LM25) and once-daily basal insulin glargine plus once-daily prandial insulin lispro (IGL) in a Latin American subpopulation (Argentina, Brazil, and Mexico) of participants with type 2 diabetes mellitus (T2D).

\section{Materials and methods}

This phase 4, randomized, open-label, parallel-arm trial included participants aged $18-75$ yrs. with T2D who were taking once-daily insulin glargine and stable doses of metformin and/or pioglitazone and had glycosylated hemoglobin (HbA1c) between $\geq 7.5 \%$ and $\leq 10.5 \%$ and fasting plasma glucose $\leq 6.7 \mathrm{mmol} / \mathrm{L}(121 \mathrm{mg} / \mathrm{dL})$. Participants were randomized 1: 1 to receive twice-daily LM25 (before breakfast and dinner) or basal insulin glargine (at bedtime) and IGL (before the largest daily meal) in addition to their existing dose of metformin and/or pioglitazone for 24 weeks. The primary efficacy outcome was the change in HbA1c from baseline to Week 24.

\section{Results}

A total of 162 participants (80 LM25; 82 IGL) with a mean (standard deviation [SD]) age of $57.3(9.0)$ yrs. and body mass index of $31.3(5.2) \mathrm{kg} / \mathrm{m} 2$ were included. The mean (SD) change in HbA1c (\%) from baseline was -1.5 (1.0) in the LM25 group and -1.0 (1.2) in the IGL group (Figure 1). At Week 24, 35.1\% of participants in the LM25 group and $31.6 \%$ of participants in the IGL group

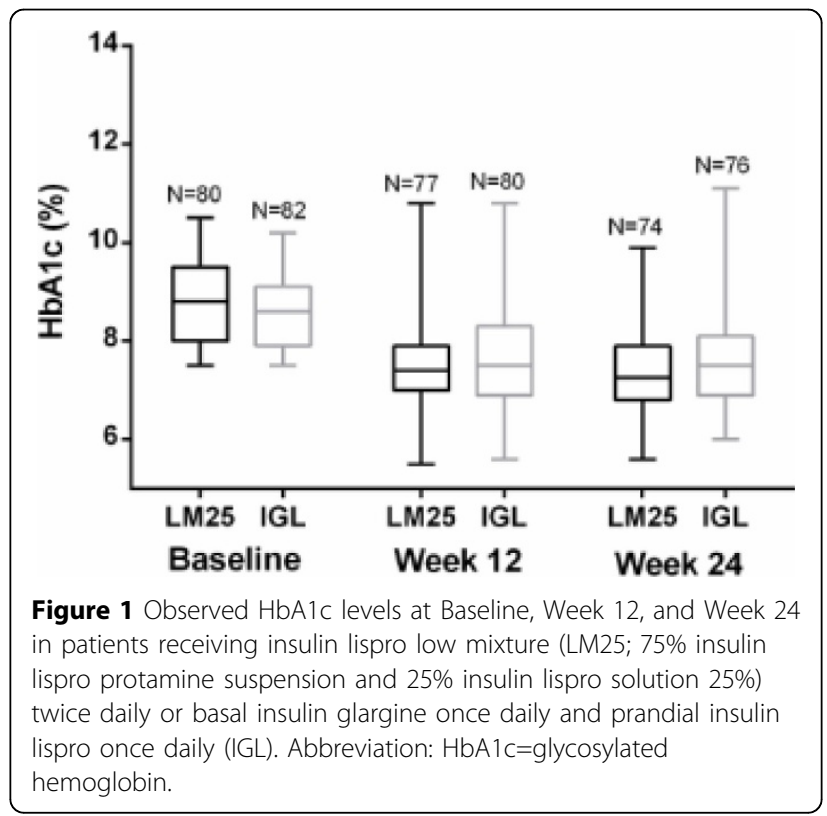

* Correspondence: dbarbieri@lilly.com

Universidade Federal de São Paulo, São Paulo, Brazil 
achieved the target HbA1c $<7.0 \%$. Fasting blood glucose and glycemic variability at Week 24 were similar between the 2 groups, as was the mean (SD) total daily insulin dose (LM25=61.0 [27.6] IU; IGL=60.6 [24.3] IU). The mean (SD) rate of total hypoglycemia per 30 days was numerically similar between the two groups (LM25=1.6 [2.2]; IGL=1.8 [2.6] [overall study period]). Mean (SD) weight gain from baseline to Week 24 was $2.4(2.9) \mathrm{kg}$ in the LM25 group and $1.0(3.1) \mathrm{kg}$ in the IGL group. Treatment-emergent adverse events were similar between the 2 groups.

\section{Conclusions}

The results of this post-hoc analysis in a Latin American population are consistent with the results reported in the trial-level population and suggest that both LM25 and IGL are viable treatment options for insulin intensification in patients with T2D who do not achieve glycemic control on basal insulin glargine. ClinicalTrials.gov Number: NCT01175824.

Published: 11 November 2015

doi:10.1186/1758-5996-7-S1-A57

Cite this article as: Barbieri et al:: Insulin lispro low mixture twice daily vs basal insulin glargine once daily and prandial insulin lispro once daily as insulin intensification strategies in patients with type 2 diabetes: A Latin American subpopulation analysis of a randomized trial. Diabetology \& Metabolic Syndrome 2015 7(Suppl 1):A57.
Submit your next manuscript to BioMed Central and take full advantage of:

- Convenient online submission

- Thorough peer review

- No space constraints or color figure charges

- Immediate publication on acceptance

- Inclusion in PubMed, CAS, Scopus and Google Scholar

- Research which is freely available for redistribution

Submit your manuscript at www.biomedcentral.com/submit
C Biomed Central 